\title{
PENGARUH DAYA TARIK WISATA, AKSESBILITAS, HARGA DAN FASILITAS TERHADAP MINAT BERKUNJUNG WISATAWAN DI OBJEK WISATA DANAU CIPONDOH, KOTA TANGERANG
}

\author{
Nurbaeti ${ }^{1}$, Myrza Rahmanita ${ }^{1}$, Heny Ratnaningtyas ${ }^{1 *}$, Amrullah $^{1}$ \\ Sekolah Tinggi Pariwisata Trisakti \\ Email: heny.ratnaningtyas@stptrisakti.ac.id
}

\begin{abstract}
Abstrak
Danau Cipondoh adalah salah satu obyek wisata yang ada di Kota Tangerang dengan daya tarik yang memiliki nilai jual, diikuti dengan aksesbilitas yang memberikan kemudahan, kemudian harga yang terjangkau, fasilitas yang cukup. Hal ini akan menjadikan Danau Cipondoh sebagai obyek wisata yang menarik bagi masyarakat Tangerang untuk berwisata. Penelitian ini bertujuan untuk mengetahui pengaruh daya tarik wisata, aksesbilitas, harga dan fasilitas terhadap minat berkunjung wisatawan di objek wisata Danau Cipondoh, Kota Tangerang. Jenis penelitian ini adalah penelitian kualitatif yang dikuantitatifkan dengan metode yang digunakan adalah regresi linier berganda dengan bantuan program SPSS 23. Teknik pengumpulan data dengan menyebarkan kuisioner kepada para wisatawan sejumlah 100 responden. Hasil penelitian secara parsial daya tarik wisata, aksesbilitas, harga dan fasilitas berpengaruh signifikan terhadap minat berkunjung wisatawan. Oleh karena itu objek wisata Danau Cipondoh harus memiliki daya tarik berupa orisinility and natural beauty, variatif, scarity, wholeness, kemudian memiliki lokasi yang mudah dijangkau, kondisi jalan yang beraspal dan berbeton, jarak waktu tempuh sangat dekat dengan Jakarta dan Tangerang Selatan. Selain itu Danau Cipondoh juga harus memiliki harga yang standar dan terjangkau juga memiliki fasilitas yang cukup meliputi parkiran, mushola, toilet, tempat istirahat, warung makan. Hal ini memberikan dampak kepada para wisatawan untuk berkali-kali berkunjung ke Danau Cipondoh. Pengelola Danau Cipondoh harus lebih mempromosikan Danau Cipondoh melalui sosial media seperti website, instagram dan facebook. Para wisatawan diharapkan tidak meninggalkan sampah yang dapat merusak keindahan di kawasan wisata Danau Cipondoh.
\end{abstract}

Kata Kunci: Daya Tarik Wisata; Aksesbilitas; Harga; Fasilitas; Minat Berkunjung Wisatawan

\begin{abstract}
Lake Cipondoh is one of the attractions in Tangerang City with an attraction that has a selling value, followed by accessibility that provides convenience, then an affordable price, adequate facilities. These attractions will make Lake Cipondoh an attractive tourist attraction for the people to travel to Tangerang. This study aims to determine the effect of tourist attraction, accessibility, price, and facilities on the interest of tourists visiting the Cipondoh Lake tourist attraction, Tangerang City. This type of research is quantitative research, with the method used is multiple linear regression with the help of the SPSS 23 program. The data collection technique is by distributing questionnaires to tourists with a total of 100 respondents. The results of the study partially tourist attraction, accessibility, price, and facilities have a significant effect on the interest of visiting tourists. Therefore, the Lake Cipondoh tourist attraction must have authenticity and natural beauty, variety, scarcity, integrity, then have an easily accessible location, asphalt, and concrete road conditions, the travel
\end{abstract}

Doi: http://dx.doi.org/10.23887/jish-undiksha.v10i2.33456 Jurnal IImu Sosial dan Humaniora| 269 
Nurbaeti, Myrza Rahmanita, Heny Ratnaningtyas, Amrullah | Pengaruh Daya Tarik Wisata, Aksesbilitas, Harga Dan Fasilitas Terhadap Minat Berkunjung Wisatawan Di Objek Wisata Danau Cipondoh, Kota Tangerang

time is very close to Jakarta and South Tangerang. In addition, Lake Cipondoh must also have standard and affordable prices and have sufficient facilities, including parking, prayer rooms, toilets, rest areas, food stalls. This condition has had an impact on tourists visiting Lake Cipondoh many times. Lake Cipondoh managers should further promote Lake Cipondoh through social media such as websites, Instagram and Facebook. The tourists are expected not to leave garbage that can damage the beauty of the Lake Cipondoh tourist area.

Keywords: Tourist Attraction; Accessibility; Price; Facilities; Tourist Visit Interest

This is an open access article under the CC BY-SA license.

Copyright @ 2021 by Author. Published by Universitas Pendidikan Ganesha.

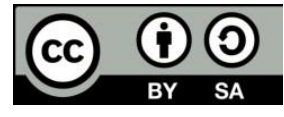

\section{PENDAHULUAN}

Tangerang menjadi salah satu kota yang dekat dengan Jakarta. Tangerang tumbuh menjadi kota yang padat dan ramai. Namun, Tangerang memiliki pariwisata yang baik dan layak dikunjungi di akhir pekan bersama teman-teman atau keluarga (Kristiana et al, 2018). Salah satu destinasi favorit warga Tangerang adalah Danau Cipondoh. Dahulu, Danau Cipondoh adalah sebuah rawa berbentuk cekungan besar yang dipenuhi oleh tumbuhan eceng gondok. Kondisinya menjadi liar dan tak terawat dengan baik. Karakteristik dan luasnya Danau Cipondoh berfungsi sebagai tandon air untuk daerah sekitarnya. Kemudian dikelola oleh swasta yaitu forum masyarakat yang berada di daerah Danau Cipondoh dengan ijin pemerintah daerah Kota Tangerang untuk dijadikan kawasan pariwisata yang tertuang pada dalam peraturan daerah No 5 Tahun 2007 situ cipondoh diperuntukan sebagai kawasan konservasi air sekaligus bagian potensi pengembangan parawisata (Kristiana, 2011).

Kunjungan wisatawan tersebut tentunya tidak terlepas dari adanya daya tarik wisata yang menarik wisatawan untuk mengunjungi obyek wisata (Ngwira, 2018). Daya tarik wisata meliputi keunikan, keindahan, kekayaan alam dan budaya dan atraksi wisata (Aprilia et al, 2017). Daya tarik
Danau Cipondoh adalah kawasan yang ramah untuk habitat fauna. Di sana, pengunjung tidak hanya menemukan jenisjenis ikan tawar tetapi juga ikan-ikan dengan jenis beragam lainnya dalam jumlah yang banyak. Ini karena terdapat campur tangan pemerintah daerah Kota Tangerang dalam menyebarluaskan beragam jenis bibit-bibit ikan untuk perkembangbiakan. Danau Cipondoh dikelola oleh masyarakat lokal, mereka membentuk forum masyarakat untuk melestarikan dan mengembangkan Danau Cipondoh dan diawasi langsung oleh Pemerintah Daerah Tangerang (Pancawati, 2019).

Selayaknya wisata alam di tengah kota, Danau Cipondoh menjanjikan pemandangan alam yang cantik dan segar terutama untuk dikunjungi di sore hari. Pengunjung akan dijanjikan pemandangan alam yang sangat cantik, terutama di waktu sore hari. Selain menjanjikan pemandangan alam yang indah, pengunjung akan turut dimanjakan dengan beberapa hiburanhiburan berupa fasilitas tambahan yang ditawarkan, diantaranya wahana bebek terapung, sepeda air, memancing, kemping dan menikmati keindahan danau dengan perahu. Destinasi tersebut menjadi favorit pengunjung sebagai sarana mengitari Danau Cipondoh (Pancawati et al, 2016).

Akses kondisi jalan menuju obyek wisata, dan jalan akses itu harus

Jurnal IImu Sosial dan Humaniora | 270 
Nurbaeti, Myrza Rahmanita, Heny Ratnaningtyas, Amrullah | Pengaruh Daya Tarik Wisata, Aksesbilitas, Harga Dan Fasilitas Terhadap Minat Berkunjung Wisatawan Di Objek Wisata Danau Cipondoh, Kota Tangerang

berhubungan dengan prasarana umum (Devile \& Kastenholz, 2018). Kondisi jalan umum dan jalan akses menentukan aksesibilitas suatu obyek wisata (Gillovic \& Mcintosh, 2020). Aksesibilitas ini merupakan syarat yang penting sekali untuk obyek wisata (Abdulhaji \& Yusuf, 2016). Lokasi Danau Cipondoh terletak di Jalan K.H Hasyim Ashari, Cipondoh, Kota Tangerang. Lokasinya berhadapan persis dengan kantor Kecamatan Cipondoh, Tangerang. Akses menuju Danau Cipondoh pun sangat mudah diakses dan dijangkau dengan beragam kendaraan baik umum atau pribadi. Jika datang dari Jakarta, melalui tol JakartaTangerang dan melewati sepanjang tol Tangerang-Merak. Keluar dari tol, melalui jalan Sultan Ageng Tirtayasa dan Jalan Jali. Banyak kendaraan umum yang melintasi obyek wisata dari Kereta KRL, Busway, Angkot dan Ojek Online. Sementara kondisi jalan menuju Danau Cipondoh sudah baik dan lancar karena jalan raya sudah beraspal beton.

Harga yang ditawarkan pada obyek wisata sangat mempengaruhi wisatawan dalam menentukan apakah mereka berminat berkunjung atau tidak, karena harga merupakan hal yang paling sensitif bagi wisatawan. Mahal atau tidaknya harga dapat dinilai sendiri oleh para wisatawan karena kebutuhan dari wisatawan itu berbeda-beda akan tetapi wisatawan cenderung lebih tartarik kepada harga yang relatif murah (Lebu et al, 2019). Pada obyek wisata Danau Cipondoh, untuk wisatawan yang membawa anak-anak dapat menikmati wahana bebek terapung dan sepeda air. Masih ada wahana ramah anak seperti ayunan, perosotan, dan kereta mini yang dapat dinikmati bersama. Bagi yang hobi mancing, pengunjung dapat memancing ikan dengan membawa bahan pancing sendiri atau membeli ditempat yang sudah disediakan. Bagi pencinta kemping, bisa berkemping di kawasan Danau Cipondoh.
Fasilitas-fasilitas penunjang ini dikenakan tarif yang bervariasi dan sangat terjangkau mulai dari Rp 5.000-Rp 30.000. Tiket masuk Danau Cipondoh pun hanya dipatok $R p$ 5.000 per orang. Selain fasilitas tambahan berbayar, pengunjung dapat menikmati sajian kuliner di sekitar Danau Cipondoh. Beberapa sajian kuliner yang dihidangkan seperti bakso, soto, rujak, hingga hidangan ikan laut. Selain itu, minuman-minuman penyegar dahaga sambil santai menikmati semilir angin danau seperti es cendol, sekoteng, kopi dan lain-lain siap menemani sambil menikmati senja di Danau Cipondoh.

Pada saat pandemic Covid-19 ini, sebelum wisatawan masuk ke objek wisata Danau Cipondoh diperiksa suhu tubuhnya, kemudian mencuci tangan dengan sabun di tempatnya yang sudah disediakan oleh pengelola wisata dan diharapkan para wisatawan menggunakan masker.

Fasilitas wisata merupakan pelengkap daerah tujuan wisata yang diperlukan untuk memenuhi kebutuhan dari wisatawan yang sedang menikmati perjalanan wisata (Jayaprakash \& Mythili, 2017). Fasilitas wisata dibuat untuk mendukung konsep atraksi wisata yang sudah ada (Sarim \& Wiyana, 2017). Selain mempunyai daya tarik wisata yang baik, aksesbilitas yang memadai dan harga terjangkau, Danau Cipondoh juga telah memiliki fasilitas yang cukup untuk wisatawan antara lain area parkiran, mushola, toilet, tempat istirahat, warung makan. Faktor-faktor tersebut mampu menarik minat wisatawan untuk berkunjung ke kawasan Danau Cipondoh serta mengajak para wisatawan setempat untuk menjaga kelestarian wisata Danau Cipondoh agar tidak meninggalkan sampah di tepian Danau Cipondoh yang dapat merusak keindahan di kawasan wisata Danau Cipondoh.

Permasalahan dalam penelitian ini adalah: (1) Daya tarik yang ada di Danau 
Nurbaeti, Myrza Rahmanita, Heny Ratnaningtyas, Amrullah | Pengaruh Daya Tarik Wisata, Aksesbilitas, Harga Dan Fasilitas Terhadap Minat Berkunjung Wisatawan Di Objek Wisata Danau Cipondoh, Kota Tangerang

Cipondoh yang berupa keindahan alam dan atraksi buatan yang sangat sederhana, apakah akan dapat menarik minat wisatawan berkunjung di obyek wisata Danau Cipondoh; (2) Aksesbilitas yang mudah dijangkau di Danau Cipondoh, apakah akan dapat menarik minat wisatawan berkunjung di obyek wisata Danau Cipondoh; (3) Harga yang sangat murah di Danau Cipondoh. apakah akan dapat menarik minat wisatawan berkunjung di obyek wisata Danau Cipondoh; (4) Fasilitas yang cukup di Danau Cipondoh, apakah akan dapat menarik minat wisatawan berkunjung di obyek wisata Danau Cipondoh.

Tujuan dalam penelitian ini adalah: (1) Untuk mengetahui pengaruh daya tarik wisata terhadap minat berkunjung wisatawan di objek wisata Danau Cipondoh; (2) Untuk mengetahui pengaruh aksesbilitas terhadap minat berkunjung wisatawan di objek wisata Danau Cipondoh; (3) Untuk mengetahui pengaruh harga terhadap minat berkunjung wisatawan di objek wisata Danau Cipondoh; (4) Untuk mengetahui pengaruh fasilitas terhadap minat berkunjung wisatawan di objek wisata Danau Cipondoh.

Manfaat dalam penelitian ini adalah: (1) Bagi peneliti bermanfaat untuk menambah pengetahuan tentang daya tarik, aksesibilitas, harga, fasilitas dan minat kunjung wisatawan; (2) Bagi peneliti selanjutnya bermanfaat untuk melakukan penelitian lebih lanjut dengan variabel yang berbeda; (3) Bagi akademik, penelitian ini bermanfaat untuk sarana pengembangan ilmu pengetahuan

\section{METODE}

Penelitian ini dilakukan di obyek wisata Danau Cipondoh, Kota Tangerang. Waktu penelitian dilaksanakan dari tanggal 1 Desember 2019 sampai tanggal 30 Maret 2020. Kuisioner digunakan dalam penelitian ini untuk pengumpulan data. Kuesioner merupakan daftar pertanyaan tertulis yang telah dirumuskan sebelumnya yang akan responden jawab, biasanya didefinisikan dengan jelas.

Seluruh wisatawan yang mengunjungi obyek wisata Danau Cipondoh, Tangerang adalah populasi dalam penelitian ini. Sedangkan sampelnya berjumlah 100 orang, karena pertimbangan waktu, uang, tenaga dan telitinya (Arikunto, 2016). Teknik pengambilan sampelnya menggunakan accidental sampling yaitu prosedur sampling yang memilih sampel dari orang yang mudah dijumpai atau diakses (Sugiyono, 2017).

Penelitian ini menggunakan metode analisis regresi berganda dengan bantuan software SPSS 23. Data dalam penelitian ini adalah data kualitatif yang dikuantitatifkan agar dapat mempermudah proses pengolahan data maka digunakan skala likert dari 1-5, terdiri dari: (1) Sangat Setuju (SS); (2) Setuju (S); (3) Netral (N); (4) Tidak Setuju (TS); (5) Sangat Tidak Setuju (STS)

\section{HASIL DAN PEMBAHASAN Hasil}

Tabel 1. Uji Validitas

\begin{tabular}{|l|l|r|r|}
\hline Variabel & $\begin{array}{l}\text { Item } \\
\text { Pertanyaan }\end{array}$ & $\begin{array}{c}\text { r- } \\
\text { hitung }\end{array}$ & $\begin{array}{c}\text { r- } \\
\text { tabel }\end{array}$ \\
\hline \multirow{4}{*}{ Waya Tarik } & DTW1 & 0,799 & 0,164 \\
\cline { 2 - 4 } & DTW2 & 0,814 & 0,164 \\
\cline { 2 - 4 } & DTW3 & 0,733 & 0,164 \\
\cline { 2 - 4 } & DTW4 & 0,761 & 0,164 \\
\cline { 2 - 4 } & DTW5 & 0,663 & 0,164 \\
\hline Aksesbilitas & AKS1 & 0,782 & 0,164 \\
\cline { 2 - 4 } & AKS2 & 0,844 & 0,164 \\
\cline { 2 - 4 } & AKS3 & 0,873 & 0,164 \\
\cline { 2 - 4 } & AKS4 & 0,825 & 0,164 \\
\cline { 2 - 4 } & AKS5 & 0,814 & 0,164 \\
\hline Harga & HRG1 & 0,719 & 0,164 \\
\cline { 2 - 4 } & HRG2 & 0,822 & 0,164 \\
\cline { 2 - 4 } & HRG3 & 0,727 & 0,164 \\
\cline { 2 - 4 } & HRG4 & 0,782 & 0,164 \\
\cline { 2 - 4 } & HRG5 & 0,692 & 0,164 \\
\hline Fasilitas & FSLTS1 & 0,721 & 0,164 \\
\cline { 2 - 4 } & FSLTS2 & 0,871 & 0,164 \\
\hline
\end{tabular}

Jurnal IImu Sosial dan Humaniora| 272 
Nurbaeti, Myrza Rahmanita, Heny Ratnaningtyas, Amrullah | Pengaruh Daya Tarik Wisata, Aksesbilitas, Harga Dan Fasilitas Terhadap Minat Berkunjung Wisatawan Di Objek Wisata Danau Cipondoh, Kota Tangerang

\begin{tabular}{|l|l|r|r|}
\hline \multirow{4}{*}{\begin{tabular}{|l|r|} 
Minat \\
Berkunjung
\end{tabular}} & FSLTS3 & 0,677 & 0,164 \\
\cline { 2 - 4 } Wisatawan & FSLTS4 & 0,792 & 0,164 \\
\cline { 2 - 4 } & FSLTS5 & 0,715 & 0,164 \\
\cline { 2 - 4 } & MBW1 & 0,661 & 0,164 \\
\cline { 2 - 4 } & MBW2 & 0,734 & 0,164 \\
\cline { 2 - 4 } & MBW3 & 0,752 & 0,164 \\
\cline { 2 - 4 } & MBW4 & 0,811 & 0,164 \\
\cline { 2 - 4 } & MBW5 & 0,735 & 0,164 \\
\hline
\end{tabular}

Sumber: Data diolah dengan SPSS 23 (2020)

Pada tabel 1 menunjukkan bahwa semua indikator adalah valid, hal ini ditandai dengan nilai r-hitung $>$ r-tabel $(0,164)$.

Tabel 2. Uji Reliabilitas

\begin{tabular}{|c|c|c|}
\hline Variabel & $\begin{array}{c}\text { Cronbach's } \\
\text { Alpha }\end{array}$ & $\begin{array}{c}\text { Nilai } \\
\text { Alpha }\end{array}$ \\
\hline DTW & 0,802 & 0,60 \\
\hline AKS & 0,911 & 0,60 \\
\hline $\mathrm{HRG}$ & 0,854 & 0,60 \\
\hline FSLTS & 0,791 & 0,60 \\
\hline MBW & 0,888 & 0,60 \\
\hline
\end{tabular}

Pada tabel 2 menunjukkan bahwa semua indikator adalah valid, hal ini ditandai dengan nilai cronbach's alpha based on standardized items $>$ nilai alpha $(0,60)$.

Tabel 3. Uji Multikolinieritas

\begin{tabular}{|l|r|r|}
\hline \multirow{2}{*}{ Model } & \multicolumn{2}{|c|}{ Collinearity Statistics } \\
\cline { 2 - 3 } & Tolerance & \multicolumn{1}{c|}{ VIF } \\
\hline (Constant) & & \\
DTW & .517 & 1.934 \\
AKS & .981 & 1.019 \\
HRG & .501 & 1.996 \\
FSLTS & .946 & 1.057 \\
\hline
\end{tabular}

Sumber: Data diolah dengan SPSS 23 (2020)

Pada tabel 3, nilai VIF pada semua variabel tidak ada yang lebih besar dari 10 . Sedangkan nilai tolerance pada semua tidak ada yang lebih kecil dari 0,10 , maka dapat dikatakan tidak terjadi multikolinieritas pada kedua variabel bebas tersebut.

Tabel 4. Uji Normalitas-1

\begin{tabular}{|l|r|r|r|}
\hline & \multicolumn{1}{|c|}{ DTW } & \multicolumn{1}{c|}{ AKS } & \multicolumn{1}{c|}{ HRG } \\
\hline $\mathrm{N}$ & 100 & 100 & 100 \\
Normal & .0000000 & .0000000 & .0000000 \\
Parameters ${ }^{\mathrm{a}, \mathrm{b}}$ & 1.688583 & 1.627982 & 1.719976 \\
& 71 & 99 & 63 \\
Most Extreme & .091 & .088 & .111 \\
Differences & .081 & .078 & .092 \\
Kolmogorov- & .091 & -.088 & -.111 \\
Smirnov Z & .091 & .088 & .111 \\
Asymp. Sig. & .368 & .200 & .401 \\
(2-tailed) \\
Sumber: Data diolah dengan SPSS 23 \\
\multicolumn{2}{|c}{ (2020) } \\
\multicolumn{2}{|l}{} \\
\end{tabular}

Tabel 5. Uji Normalitas-2

\begin{tabular}{|l|r|r|}
\hline & \multicolumn{1}{|c|}{ FSLTS } & \multicolumn{1}{c|}{ MBW } \\
\hline $\mathrm{N}$ & 100 & 100 \\
Normal Parameters $\mathrm{a}, \mathrm{b}$ & .0000000 & .0000000 \\
& 1.42988279 & 1.7002784 \\
& 3 & \\
Most Extreme & .076 & .109 \\
Differences & .053 & .097 \\
Kolmogorov-Smirnov Z & .076 & -.109 \\
Asymp. Sig. (2-tailed) & .076 & .109 \\
\hline
\end{tabular}

Sumber: Data diolah dengan SPSS 23 (2020)

Pada tabel 4 dan 5, nilai asymp. sig. (2-tailed) pada masing-masing variabel di atas menunjukkan lebih besar dari 0,05, sehingga dapat disimpulkan bahwa residual terdistribusi normal yang artinya asumsi klasik tentang kenormalan telah dipenuhi.

Tabel 6. Uji Autokorelasi

\begin{tabular}{|l|l|}
\hline Model & Durbin-Watson \\
\hline 1 & 2.105 \\
\hline
\end{tabular}

Sumber: Data diolah dengan SPSS 23 (2020) 
Nurbaeti, Myrza Rahmanita, Heny Ratnaningtyas, Amrullah | Pengaruh Daya Tarik Wisata, Aksesbilitas, Harga Dan Fasilitas Terhadap Minat Berkunjung Wisatawan Di Objek Wisata Danau Cipondoh, Kota Tangerang

Nilai tabel Durbin Watson pada $\alpha=$ $5 \%, \mathrm{n}=100, \mathrm{k}-1=5$, adalah $\mathrm{dL}=1,5710$ dan $\mathrm{dU}=1,7804$. Pada tabel 6 menunjukkan nilai Durbin Watson sebesar 2,105 nilai tersebut berada diantara dU dan (4-dU) yaitu 1,7804 $<2,105<2,2196$, sehingga tidak ada masalah autokorelasi.

Tabel 7. Koefesien Determinasi

\begin{tabular}{|c|c|c|c|}
\hline $\mathrm{R}$ & $\begin{array}{c}\mathrm{R} \\
\text { Square }\end{array}$ & $\begin{array}{c}\text { Adjusted } \\
\mathrm{R} \\
\text { Square }\end{array}$ & $\begin{array}{c}\text { Std. Error of the } \\
\text { Estimate }\end{array}$ \\
\hline $.872^{\mathrm{a}}$ & .760 & .750 & .29023 \\
\hline
\end{tabular}

Pada tabel 7 , nilai adjusted $R^{2}$ yaitu sebesar 0,750 atau $75 \%$. Hal ini berarti $75 \%$, variasi minat berkunjung wisatawan (MBW) DAPAT dijelaskan oleh variasi dari keempat variabel bebas yaitu daya tarik wisata (DTW), aksesbilitas (AKS), harga (HRG) dan fasilitas (FSLTS). Sedangkan sisanya sebesar $25 \%$ dijelaskan oleh sebab-sebab lain di luar model atau variabel lain yang belum diteliti dalam penelitian ini.

Tabel 8. Uji F

\begin{tabular}{|c|c|c|c|c|c|}
\hline Model & $\begin{array}{c}\text { Sum of } \\
\text { Square } \\
s\end{array}$ & $\mathrm{df}$ & $\begin{array}{l}\text { Mean } \\
\text { Squar } \\
\text { e }\end{array}$ & $F$ & Sig. \\
\hline $\begin{array}{l}\text { Regressio } \\
\mathrm{n} \\
\text { Residual } \\
\text { Total }\end{array}$ & $\begin{array}{r}25.300 \\
8.002 \\
33.302 \\
\end{array}$ & $\begin{array}{r}4 \\
95 \\
99 \\
\end{array}$ & $\begin{array}{r}6.325 \\
.084\end{array}$ & $\begin{array}{r}75.0 \\
91\end{array}$ & .000 \\
\hline
\end{tabular}

Dari tabel 8, nilai F-hitung $(19,369)$ $>$ F-tabel $(2,46)$ dan nilai probabilitas 0,000 $<0,05$. Dengan demikian $\mathrm{H}_{0}$ ditolak dan $\mathrm{H}_{\mathrm{a}}$ diterima yang artinya bahwa daya tarik wisata (DTW), aksesbilitas (AKS), harga (HRG) dan fasilitas (FSLTS) secara bersama-sama berpengaruh signifikan terhadap minat berkunjung wisatawan (MBW).

Tabel 9. Uji t

\begin{tabular}{|c|c|c|c|c|c|}
\hline \multirow[t]{2}{*}{ Model } & \multicolumn{2}{|c|}{$\begin{array}{l}\text { Unstandardiz } \\
\text { ed } \\
\text { Coefficients }\end{array}$} & $\begin{array}{l}\text { Standard } \\
\text { ized } \\
\text { Coefficie }\end{array}$ & $t$ & Sig. \\
\hline & $B$ & $\begin{array}{l}\text { Std. } \\
\text { Error }\end{array}$ & Beta & & \\
\hline C & 1.909 & .676 & & 2.826 & .006 \\
\hline DTW & .297 & .077 & .269 & 3.847 & .000 \\
\hline AKS & .415 & . 147 & .143 & 2.817 & .000 \\
\hline HRG & .656 & .069 & .671 & 9.448 & .006 \\
\hline FSLTS & .264 & .101 & .135 & 2.603 & .011 \\
\hline
\end{tabular}

Untuk variabel daya tarik wisata (DTW), nilai t-hitung $(3,847)>$ t-tabel $(1,983)$ dan nilai probabilitas $0,000>0,05$. Dengan demikian $\mathrm{H}_{0}$ ditolak dan $\mathrm{H}_{\mathrm{a}}$ diterima yang artinya bahwa variabel daya tarik wisata (DTW) secara parsial berpengaruh signifikan terhadap minat berkunjung wisatawan (MBW).

Untuk variabel aksesbilitas (AKS), nilai t-hitung $(2,817)>$ t-tabel $(1,983)$ dan nilai probabilitas $0,000<0,05$. Dengan demikian $\mathrm{H}_{0}$ ditolak dan $\mathrm{H}_{a}$ diterima yang artinya bahwa aksesbilitas (AKS) secara parsial berpengaruh signifikan terhadap minat berkunjung wisatawan (MBW).

Untuk variabel harga (HRG), nilai thitung $(9,448)>$ t-tabel $(1,983)$ dan nilai probabilitas $0,000>0,05$. Dengan demikian $\mathrm{H}_{0}$ ditolak dan $\mathrm{H}_{\mathrm{a}}$ diterima yang artinya bahwa variabel harga (HRG) secara parsial berpengaruh signifikan terhadap minat berkunjung wisatawan (MBW).

Untuk variabel fasilitas (FSLTS), nilai t-hitung $(2,603)>$ t-tabel $(1,983)$ dan nilai probabilitas $0,001<0,05$. Dengan demikian $\mathrm{H}_{0}$ ditolak dan $\mathrm{H}_{\mathrm{a}}$ diterima yang artinya bahwa fasilitas (FSLTS) secara parsial berpengaruh signifikan terhadap minat berkunjung wisatawan (MBW).

Jurnal IImu Sosial dan Humaniora| 274 
Nurbaeti, Myrza Rahmanita, Heny Ratnaningtyas, Amrullah | Pengaruh Daya Tarik Wisata, Aksesbilitas, Harga Dan Fasilitas Terhadap Minat Berkunjung Wisatawan Di Objek Wisata Danau Cipondoh, Kota Tangerang

Berdasarkan hasil penelitian bahwa variabel daya tarik wisata (DTW) secara parsial berpengaruh signifikan terhadap minat berkunjung wisatawan (MBW), hal ini sejalan dengan penelitian yang dilakukan Sondakh \& Tumbel (2016) dan Alfitriani, et al (2021) bahwa Keindahan alam dan atraksi wisata yang dipelihara dan dikelola dengan baik akan menjadikan objek wisata tersebut memiliki daya tarik sehingga wisatawan ingin berkunjung pada objek wisata dan memuaskan untuk tujuan rekreasi dan menikmati perjalanannya. Pengelola Danau Cipondoh telah menjaga keaslian dan keindahan alam Danau Cipondoh yang meliputi kumpulan air danau dengan warna hijau yang indah, dimana dipinggir-pinggir danau itu ditumbuhi banyaknya tumbuhan eceng gondok. Objek wisata pun harus memiliki atraksi buatan yang bervariasi dan inovatif agar wisatawan merasa betah, seperti adanya wahana permainan air yaitu bebek terapung dan sepeda air, wahana ramah anak seperti ayunan, perosotan, dan kereta mini wisata memancing, aktivitas berkemping, menikmati moment sunset dengan menggunakan perahu kecil.

Berdasarkan hasil penelitian bahwa variabel aksesbilitas (AKS) secara parsial berpengaruh signifikan terhadap minat berkunjung wisatawan (MBW), hal ini sejalan dengan penelitian yang dilakukan Abdulhaji \& Yusuf (2016) dan Marpaung \& Sahla (2017) bahwa keberadaan objek wisata yang menarik dibutuhkan sarana dan prasarana yang memadahi guna mendukung kenyamanan wisatawan dalam berwisata. Semakin mudah aksesbilitas tersebut dicapai maka semakin tinggi minat kunjungan wisatawan yang berkunjung di objek wisata. Danau Cipondoh telah memiliki aksesbilitas yang sangat mudah dijangkau, akses menuju Situ Cipondoh yaitu Dari Jakarta Barat bisa melewati Poris ataupun Green Lake serta Karang Tengah. Dari Jakarta Selatan bisa melalui Jalan HOS Cokroaminoto yang berada di kawasan
Ciledug. Dari Alam Sutera atau kebon Nanas, akses cepat melalui Jalan Tol Jakarta-Merak. Jalan menuju Danau Cipondoh sudah beraspal beton dengan kondisi baik dan lokasi Danau Cipondoh dekat dengan warga karena di sekeliling situ terdapat banyak perumahan padat penduduk yang berada dalam wilayah Kota Tangerang.

Berdasarkan hasil penelitian bahwa variabel harga (HRG)) secara parsial berpengaruh signifikan terhadap minat berkunjung wisatawan (MBW), hal ini sejalan dengan penelitian yang dilakukan oleh Gusful \& Prasetyo (2015) dan Riyanti, et al (2020) bahwa harga yang terjangkau yang ditawarkan oleh objek wisata akan memberi dampak pada kunjungan wisata yang terus menerus pada wisatawan terutama pada wisatawan yang memiliki pendapatan/gaji yang tidak besar. Pengelola Danau Cipondoh telah menetapkan harga yang standar dan terjangkau sehingga para wisatawan berminat berkunjung untuk berkali-kali ke Danau Cipondoh: (1) Tiket masuk ke Danau Cipondoh dikenakan biaya Rp 5.000; (2) Wahana ramah anak seperti ayunan, perosotan, dan kereta mini yang dapat dinikmati bersama dikenakan biaya Rp 10.000; (3) Menikmati wahana bebek terapung membayar Rp 5.000; (4) Menikmati sepeda air membayar Rp 25.000; (5) Menikmati moment sunset dengan menggunakan perahu kecil $\mathrm{Rp}$ 15.000; (6) Berkemping Rp 30.000 dengan menyewakan tempat dan alat-alat tenda; (7) Menikmati wisata memancing Rp 10.000; (8) Menikmati wisata kuliner dengan dengan banyaknya warung-warung jajan sederhana di sekitar pelataran Danau Cipondoh, harga makanan tersebut dari Rp $5.000 \mathrm{~s} / \mathrm{d} \mathrm{Rp}$ 50.000

Berdasarkan hasil penelitian bahwa variabel fasilitas (FSLTS) secara parsial berpengaruh signifikan terhadap minat berkunjung wisatawan (MBW), hal ini sejalan dengan penelitian yang dilakukan

Jurnal IImu Sosial dan Humaniora| 275 
Nurbaeti, Myrza Rahmanita, Heny Ratnaningtyas, Amrullah | Pengaruh Daya Tarik Wisata, Aksesbilitas, Harga Dan Fasilitas Terhadap Minat Berkunjung Wisatawan Di Objek Wisata Danau Cipondoh, Kota Tangerang

oleh Fitriani \& Wilardjo (2018) dan Iswidyamarsha \& Dewantara (2020) bahwa Fasilitas yang lengkap dan memadai serta standar pelayanan telah dipenuhi oleh obyek wisata maka akan menarik wisatawan berkunjung di tempat wisata tersebut. Danau Cipondoh telah memiliki fasilitas yang cukup untuk wisatawan antara lain area parkiran, mushola, toilet, tempat istirahat dan warung makan.

\section{SIMPULAN DAN SARAN}

Adanya pengaruh yang sangat signifikan daya tarik wisata (DTW) terhadap minat berkunjung wisatawan (MBW) karena objek wisata Danau Cipondoh memiliki orisinility and natural beauty, variatif, scarity, wholeness yang menjadikan unsur yang penting dan motivasi para wisatawan untuk berkunjung pada obyek wisata yang mempunyai keterpaduan dengan sarana pariwisata. Adanya pengaruh yang sangat signifikan aksesbilitas (AKS) terhadap minat berkunjung wisatawan (MBW) karena objek wisata Danau Cipondoh memiliki lokasi yang mudah dijangkau, kondisi jalan yang beraspal dan berbeton, jarak waktu tempuh sangat dekat dengan DKI Jakarta dan Tangerang Selatan. Adanya pengaruh yang sangat signifikan harga (HRG)) terhadap minat berkunjung wisatawan (MBW) karena objek wisata Danau Cipondoh memiliki harga yang standar dan terjangkau sehingga para wisatawan berminat berkunjung untuk berkali-kali ke Danau Cipondoh. Adanya pengaruh yang sangat signifikan fasilitas (FSLTS) terhadap minat berkunjung wisatawan (MBW). Hal ini disebabkan karena objek wisata Danau Cipondoh telah memiliki fasilitas yang lengkap untuk wisatawan antara lain area parkiran, mushola, toilet, tempat istirahat, warung makan, dan lain-lain.

Didalam penelitian ini, variabel yang sangat besar berpengaruh signifikan dengan minat berkunjung wisatawan
(MBW)adalah harga, oleh karena itu untuk mendukung peran harga sebagai strategi wisata, maka pengelola Danau Cipondoh harus lebih aktif berinteraksi dan mempublikasian informasi mengenai Danau Cipondoh melalui sosial media seperti Danau Cipondoh harus memiliki sendiri website, instagram dan facebook dengan mempromosikan objek wisata tersebut.

Untuk para wisatawan diharapkan menjaga kelestarian wisata Danau Cipondoh agar tidak meninggalkan sampah yang dapat merusak keindahan di kawasan wisata Danau Cipondoh.

Untuk peneliti selanjutnya, agar variabel penelitian ini diperluas, maka tidak hanya daya tarik wisata, aksesbilitas, fasilitas dan harga tetapi juga variabelvariabel lainnya yang dapat mempengaruhi keputusan berkunjung yaitu produk, kualitas pelayanan, promosi dan lain-lain.

\section{DAFTAR PUSTAKA}

Alfitriani., Putri, W. A., \& Ummasyroh. (2021). Pengaruh Komponen 4A Terhadap Minat Kunjung Ulang Wisatawan Pada Destinasi Wisata Bayt Al-Qur'an Al-Akbar Kota Palembang. JAMB (Jurnal Aplikasi Manajemen \& Bisnis), 1(2): 66-77.

Abdulhaji, S., \& Yusuf, I. S. (2016). Pengaruh Atraksi, Aksesibilitas dan Fasilitas Terhadap Citra Objek Wisata Danau Tolire Besar di Kota Ternate. Jurnal Penelitian Humano, 2(7): 134148.

Aprilia, E. R., Sunarti., \& Pangestuti, E. (2017). Pengaruh Daya Tarik Wisata Dan Fasilitas Layanan Terhadap Kepuasan Wisatawan Di Pantai Balekambang Kabupaten Malang. Jurnal Administrasi Bisnis (JAB), 51(2): 16-21.

Arikunto, S. (2016). Prosedur Penelitian Suatu Pendekatan Praktik. Jakarta: Rineka Cipta.

Jurnal IImu Sosial dan Humaniora| 276 
Nurbaeti, Myrza Rahmanita, Heny Ratnaningtyas, Amrullah | Pengaruh Daya Tarik Wisata, Aksesbilitas, Harga Dan Fasilitas Terhadap Minat Berkunjung Wisatawan Di Objek Wisata Danau Cipondoh, Kota Tangerang

Devile, E., \& Kastenholz, E. (2018). Accessible Tourism Experiences: The Voice of People with Visual Disabilities. Journal of Policy Research in Tourism in Tourism Leisure and Events: 1-20.

Fitriani, R., \& Wilardjo, S. B. (2018). Sadar Wisata, Kemenarikan Fasilitas, Jarak, Pengaruhnya Terhadap Minat Berkunjung Kembali Pada Objek Wisata Masjid Agung Jawa Tengah Di Kota Semarang. Jurnal Wawasan Manajemen, 5(3): 259-272.

Gillovic, B., \& Mclntosh, A. (2020). Accessibility and Inclusive Tourism Development: Current State and Future Agenda. Sustainability: 1-15

Gusful, A., \& Prasetyo, B. (2015). Analisis Faktor-Faktor Yang Mempengaruhi Wisatawan Dalam Berkunjung di Taman Rekreasi Kalianget Wonosobo. Jurnal IImiah Ekonomi Manajemen dan Akuntansi, 10(1): 124.

Iswidyamarsha, C., \& Dewantara, Y. F. (2020). Pengaruh Fasilitas Wisata Dan Promosi Terhadap Minat Berkunjung Di Dunia Air Tawar Dan Dunia Serangga TMII. Sadar Wisata: Jurnal Pariwisata, 3(2): 72-80.

Jayaprakash, K., \& Mythili, B. (2017). Tousrist Satisfaction Level on Destination Facilities in The Nilgiris. EPRA International Journal of Economic and Business Review, 5(9): 122-126.

Kristiana, Y., Suryadi, M. T., \& Sunarya, S. R. (2018). Eksplorasi Potensi Wisata Kuliner Untuk Pengembangan Pariwisata Di Kota Tangerang. Jurnal Khasanah, 9(1): 18-23.

Kristiana, Y. (2011). Potensi Situ Cipondoh Sebagai Kawasan Wisata dan Fungsi Konservasi di Kotamadya Tangerang. Hosptour, 2(1): 115-132.

Lebu, C. F. K., Mandey, S. L., \& Wenas, R.S. (2019). Pengaruh Lokasi, Persepsi
Harga Dan Daya Tarik Wisata Terhadap Keputusan Berkunjung Wisatawan Di Objek Wisata Danau Linow. Jurnal EMBA, 7(4): 5505:5513. Marpaung, H., \& Sahla, H. (2017). Pengaruh Daya Tarik Dan Aksesibilitas Terhadap Minat Berkunjung Wisatawan Ke Air Terjun Ponot Di Desa Tangga Kecamatan Aek Songsongan Kabupaten Asahan. Prosiding Seminar Nasional Multidisiplin IImu UNA, 1151-1160.

Ngwira, C. (2018). What attracts tourists to a destination? Is it attractions?. African Journal of Hospitality, Tourism and Leisure, 7(1): 1-19.

Pancawati, J. (2019). Potensi Pengembangan Kegiatan Budidaya Ikan Di Perairan Situ Cipondoh. Agrosamudra, Jurnal Penelitian, 6(2): 16-25.

Pancawati, J., Saifullah., \& Indaryanto, F. R. (2016). Valuation of Recreational Fishing in Situ Cipondoh Using Travel Cost Approach. Jurnal Perikanan dan Kelautan, 6(1): 51-60.

Riyanti, N. K. I., Kusuma, I. G. A. N. E. T., \& Rihayana. Pengaruh Kualitas Pelayanan, Harga, dan Promosi Terhadap Niat Berkunjung Kembali di Villa Rendezvous Bali. Widya Amerta Jurnal Manajemen Fak. Ekonomi, 7(1): 84-99.

Sarim., \& Wiyana, T. (2017). Pengaruh Fasilitas Wisatawan Terhadap Motivasi Kunjungan Wisatawan (Studi Kasus Kunjungan Wisatawan Kota Solo). Jurnal Hospitality dan Pariwisata, 3(2): 342-249.

Sondakh, P. M., \& Tumbel, A. (2016). Pelayanan Keamanan dan Daya Tarik Mempengaruhi Minat Wisatawan yang Berkunjung Ke Objek Wisata Alam Gunung Mahawu, Tumohon. Jurnal Berkala IImiah Efisiensi, 16(1): 280-288.

Jurnal IImu Sosial dan Humaniora | 277 
Nurbaeti, Myrza Rahmanita, Heny Ratnaningtyas, Amrullah | Pengaruh Daya Tarik Wisata, Aksesbilitas, Harga Dan Fasilitas Terhadap Minat Berkunjung Wisatawan Di Objek Wisata Danau Cipondoh, Kota Tangerang

Sugiyono. (2017). Metode Penelitian

Kuantitatif, Kualitatif, dan R\&D.

Bandung: CV. Alfabeta. 